\title{
التطور الحضاري لبركة الأزبكية منذ النشأة وحتي نهاية العصر المملوكي
}

\author{
د/ شيماء عبد الفتاح عحم عبد الفتاح
}

مدير إدارة تسجيل الاثار بقطاع الأثار الإسلامية والقبطة واليهودية - وزارة السياحة والأثار

المقدمة:-

تعتبر منطقة الأزبكية من أهم المناطق التى مر عليها العديد من الأحداث التى أثرت فيها سلبًا وايجابًا

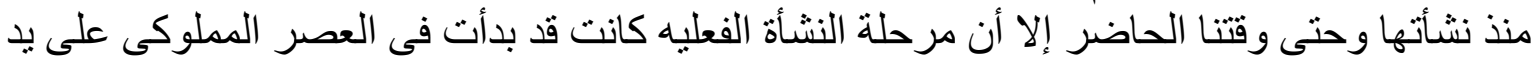

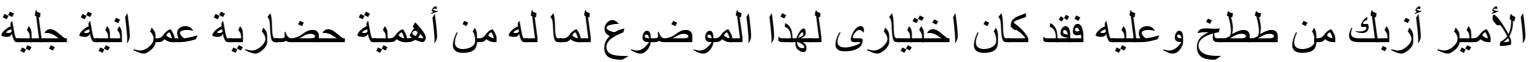

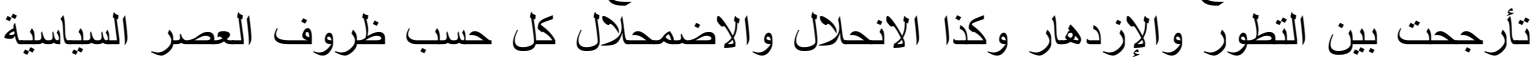
و الإجتماعية .

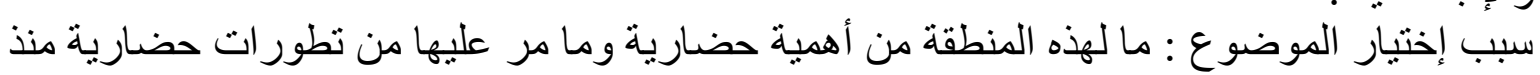

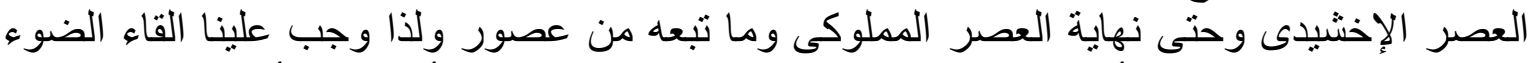
على منطقة كهذه ينبغى أن نفرد لها كتب ومجلدات حتى نستطيع أن نبرز أهميتها الحضارية

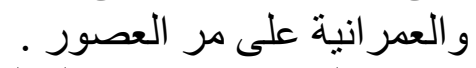
* هدف البحث:ابراز دور الدولة فى الإهتمام بالبرك و المنتز هات و العائد على المجتمع من هذه الأعمال

منهج البحث: قسم هذا البحث إلى عدة محاور حيث بدأ بمقدة بسيطة تبعها المحور الأول عن النشأة

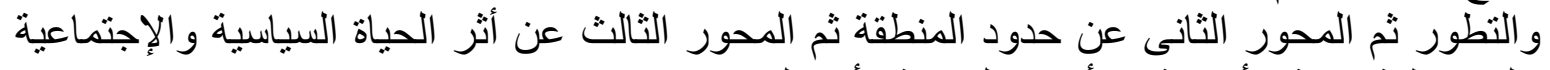
على منطقة بركة الأزبكية ، و أخيرًا الخاتمة و وأهم النتائج .

\section{ـ النشأة الجيولوجية}

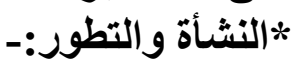

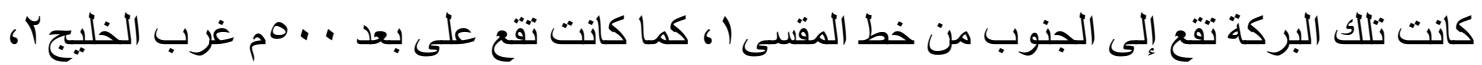

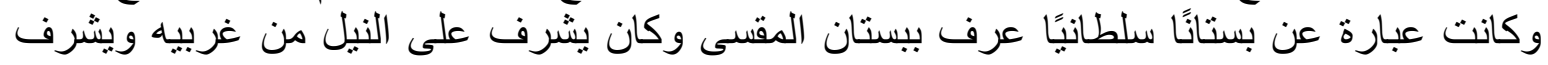

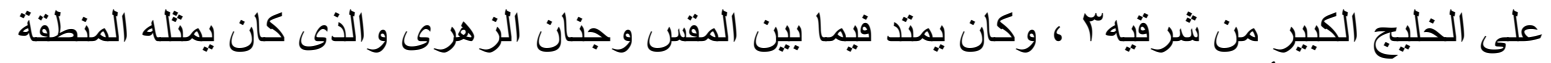

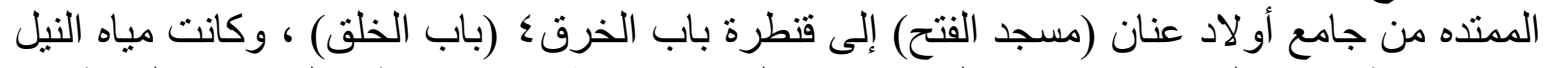

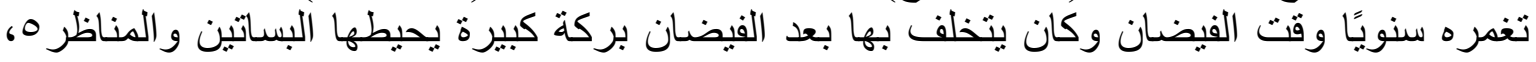

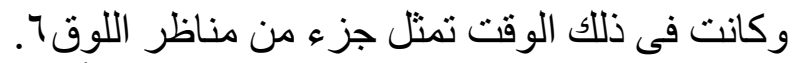

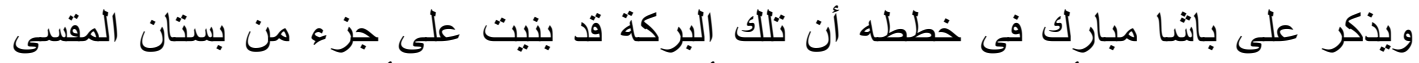

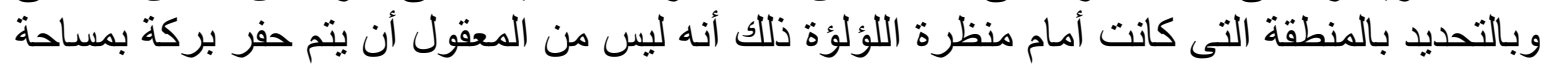

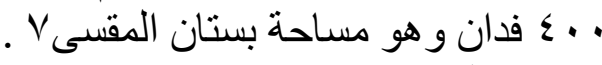

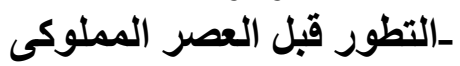

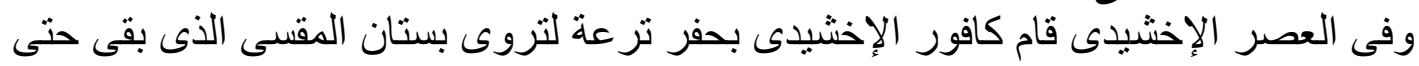

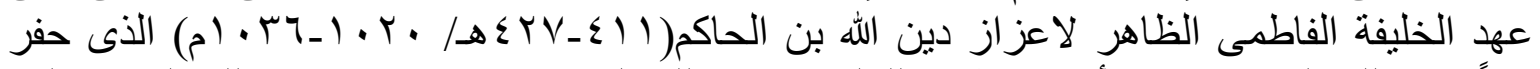

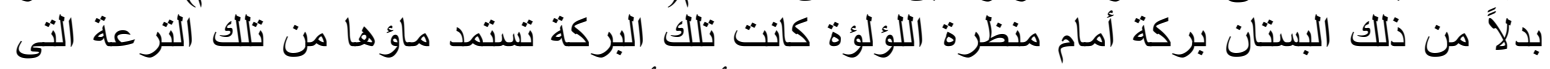

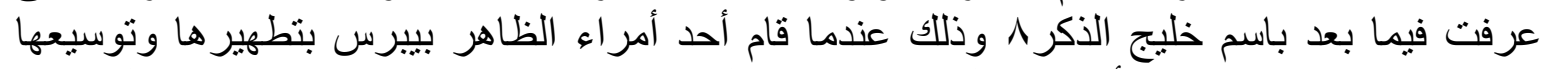

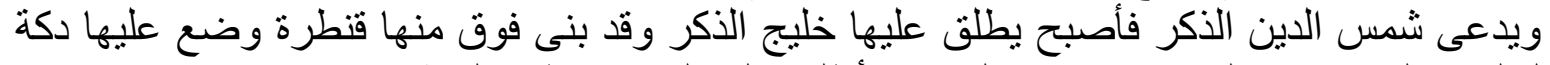

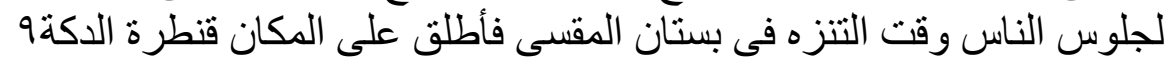

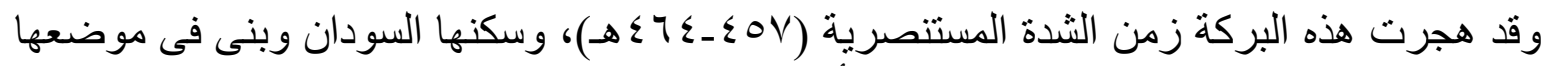

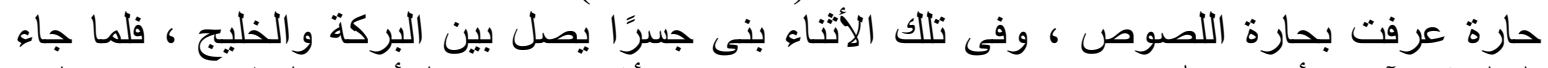

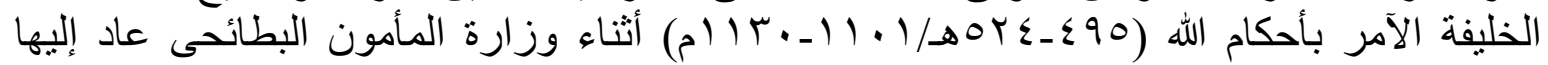


العمر ان حيث أزيلت تللك الأبنية التى كان قد اختطها السودان ومن بينها الجسر المذكور ، و وأعيد حفر

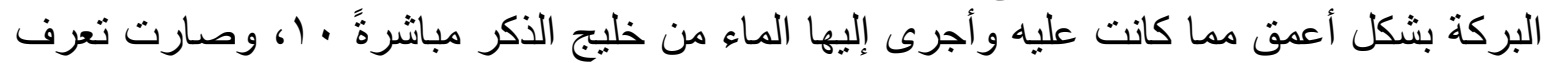

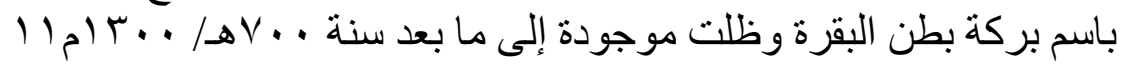

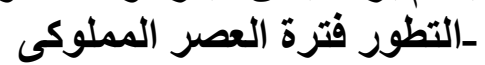

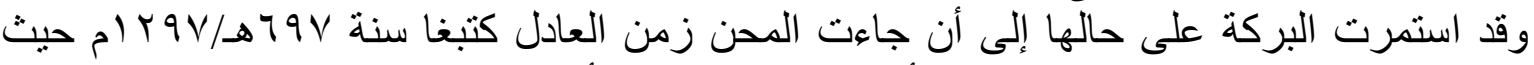

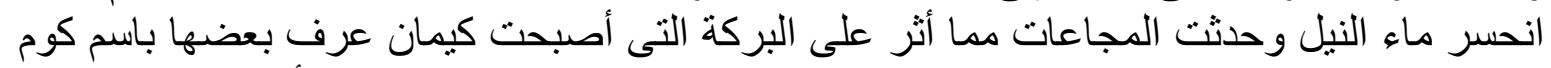

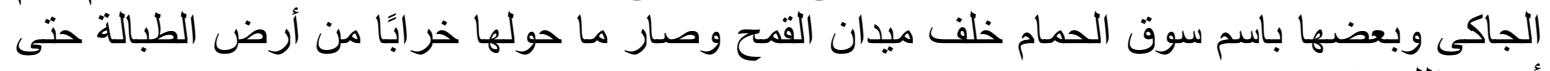

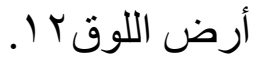

ولما ردم خليج الذكر أهملت البركة وصار موضعها طريق مقطوع مهمل ملئ بالتلال

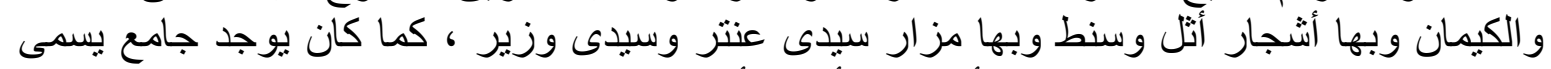

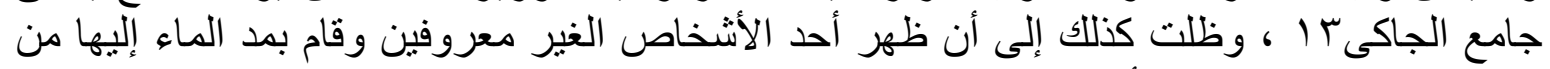

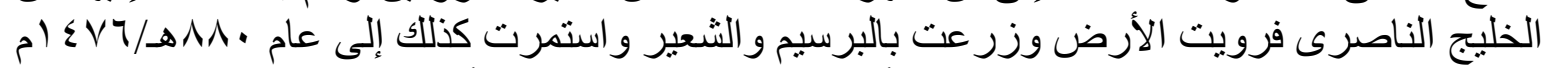

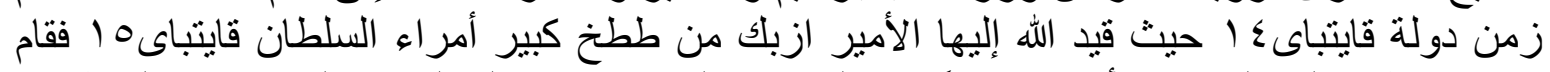

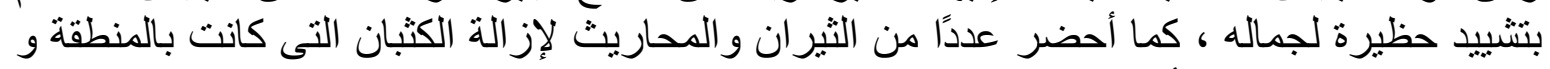

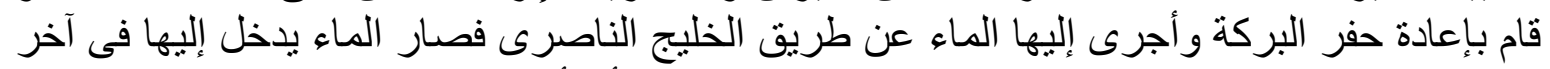

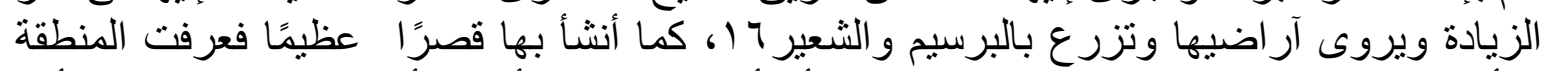

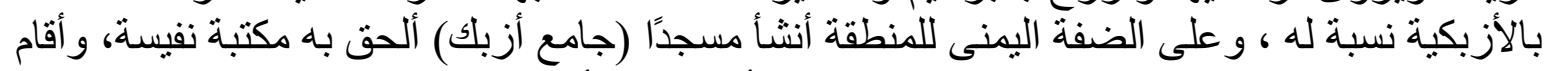

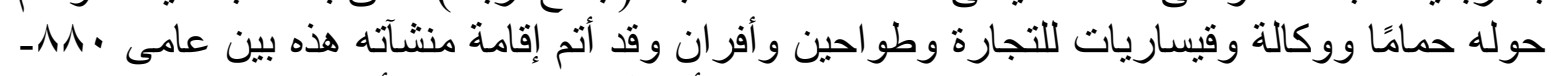
أعهاله هـ/19

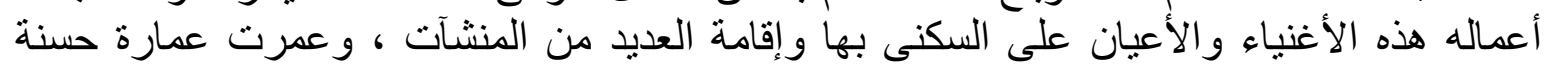

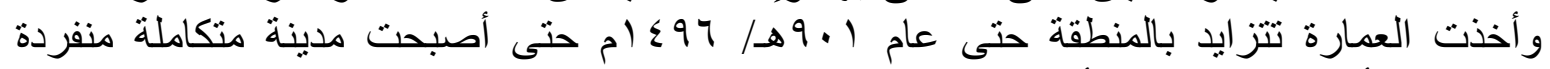

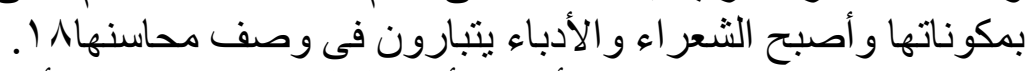

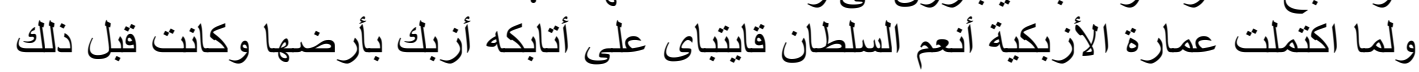

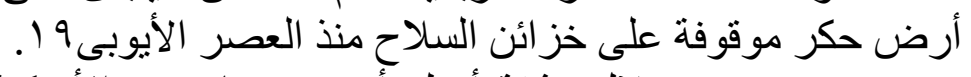

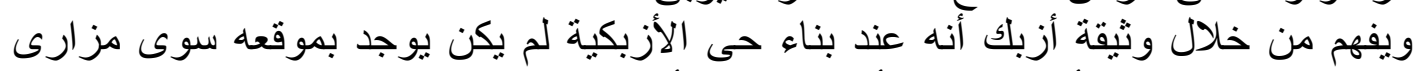

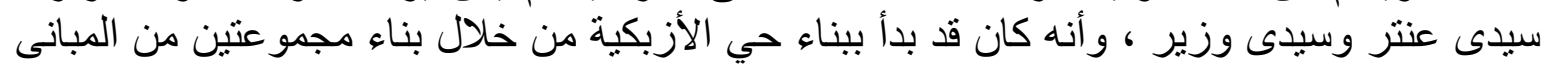

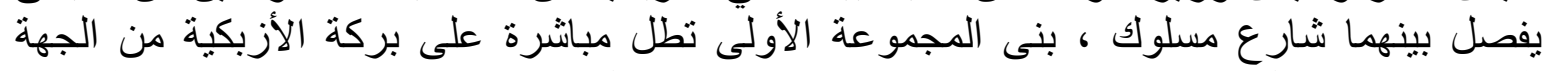

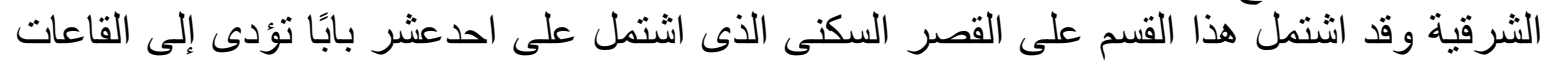

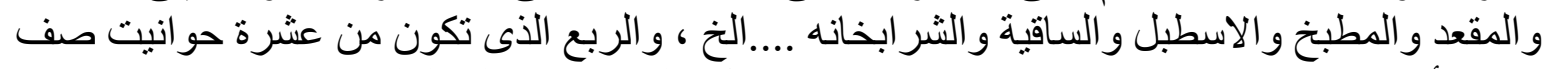

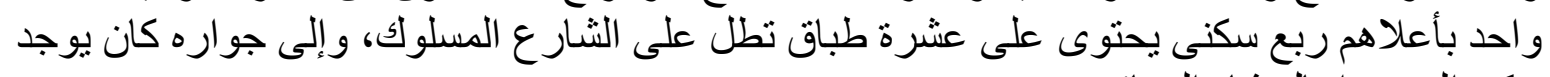

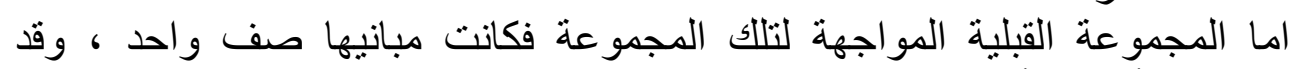
سكن السيفى اينال شاد العمائر .

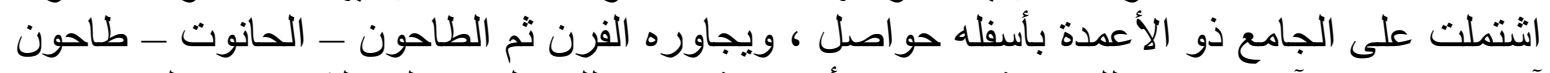

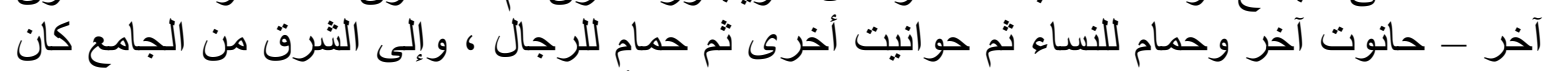

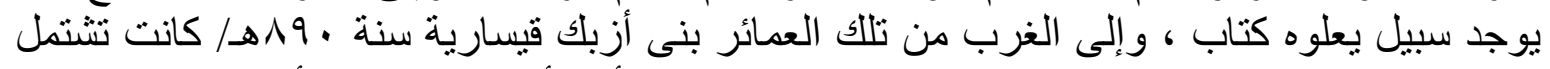

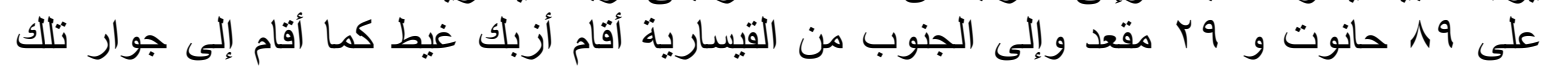

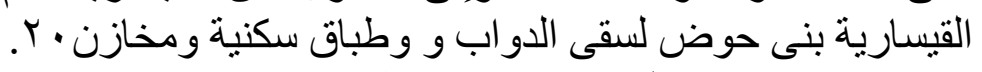

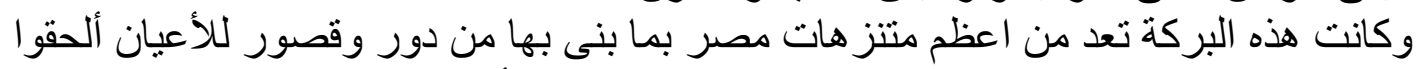

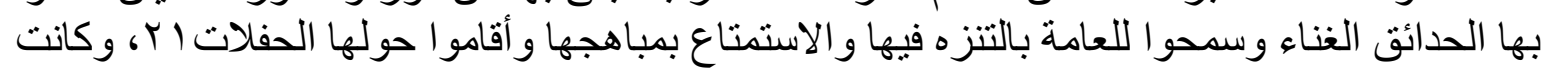

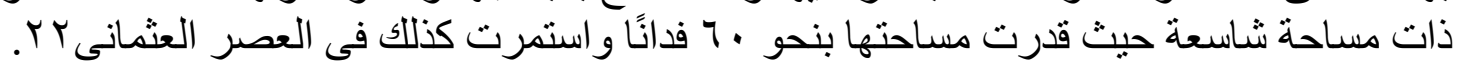
حدود البركة :- دات مدان

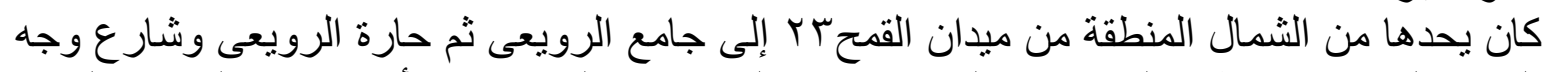

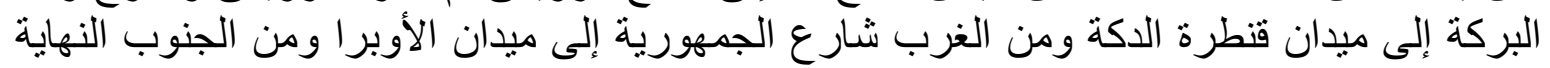


القبلية لمبدان الأوبرا وشارع طاهر وشارع الموسكى، ومن الثرق الخط الموازى للخليج المصرى

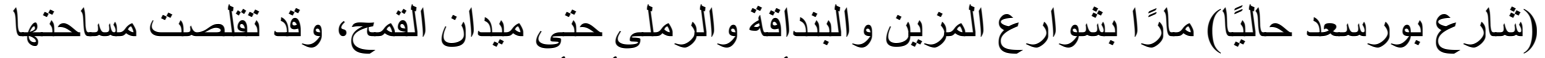

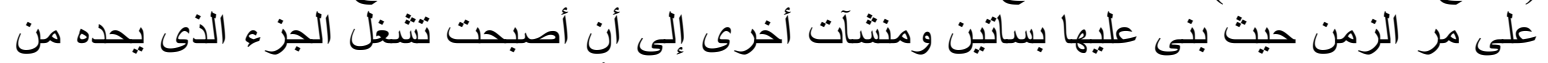

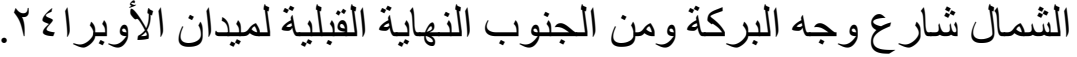

*أثز الحياة الإجتماعية و السياسية كثثرًا ما كانت تتااثر منطقة الأزبكية بسبب الأحداث السياسية التى كانت نؤثر ايجابا او سلبيًا على التى

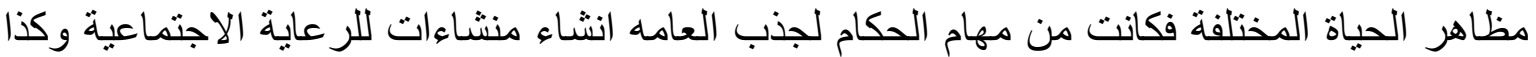
البرك و البساتين للتنزة الا انه بتغير الفترات السياسية يحدث اضمحلال مما ينعكس على هذه المناطق

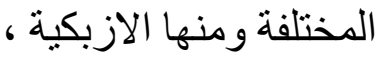

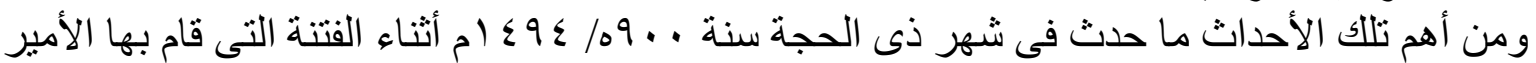

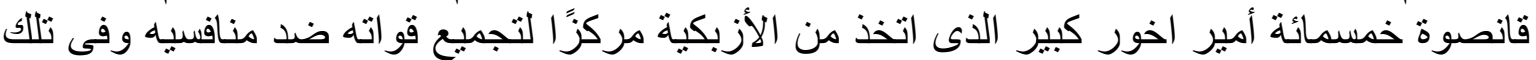

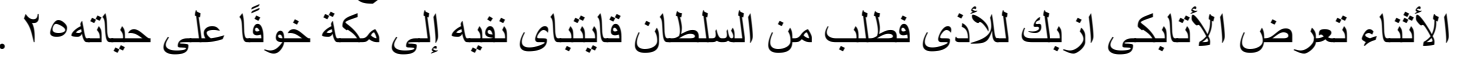

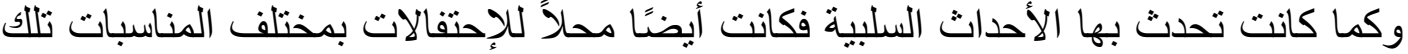

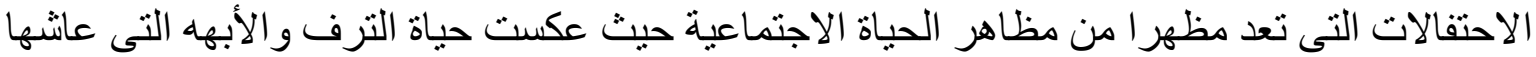

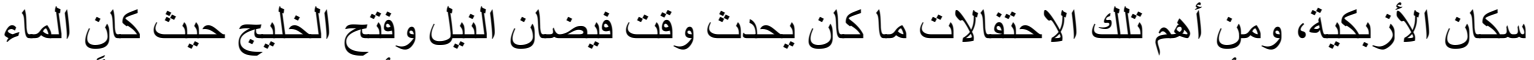

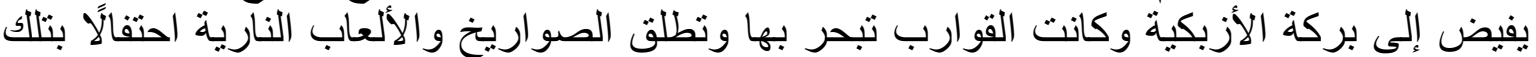

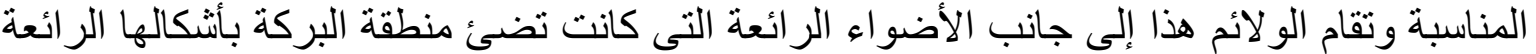

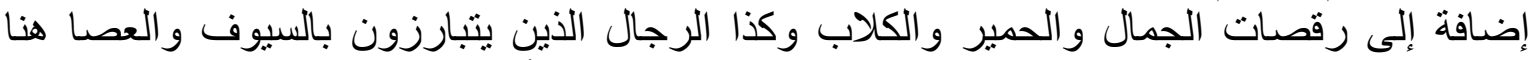

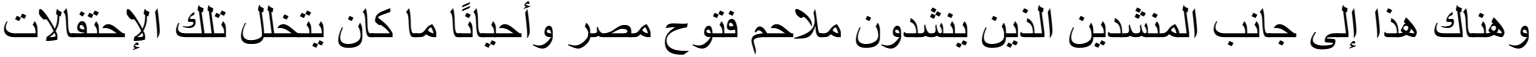

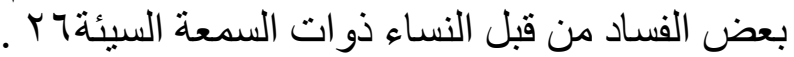
وقد تعرضت الأزبكية للنهب واء التخريب أيام السلطان الغورى كما تعرضت للامار أكثر أثناء

و الجدير بالذكر أن قصر أزبك أصبح فيما بعد مخصص لكل من يتولى وظيفة الأتابكية بمصر

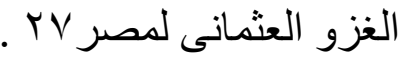

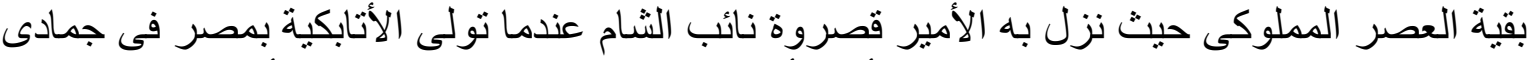

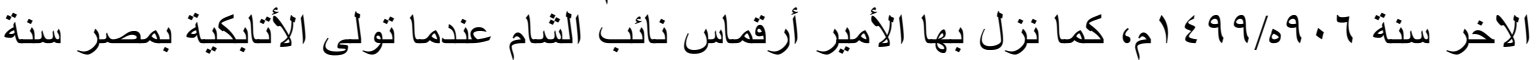
$\left.r \wedge_{0}\right) 0 . \varepsilon / 0911$

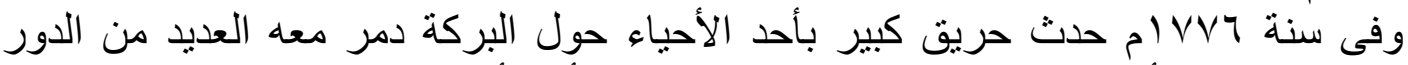

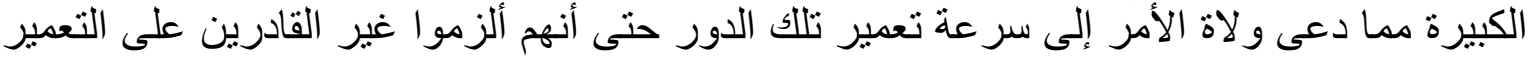

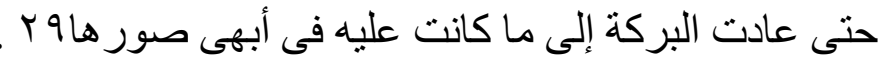
الخاتمة و أهم النتائج

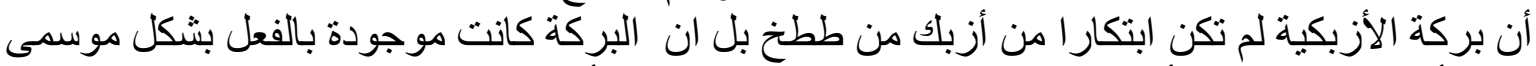

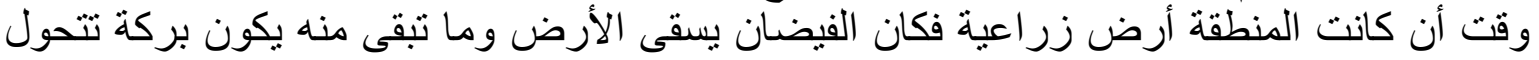

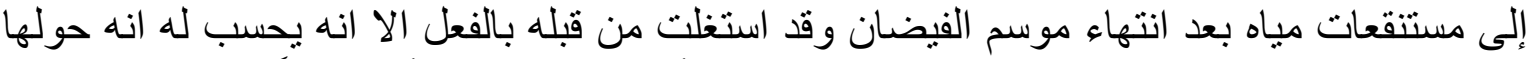

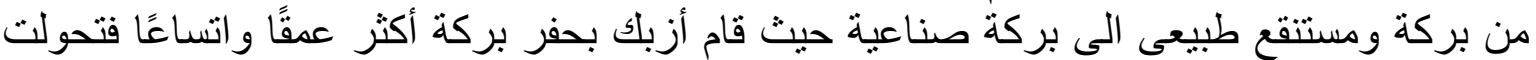

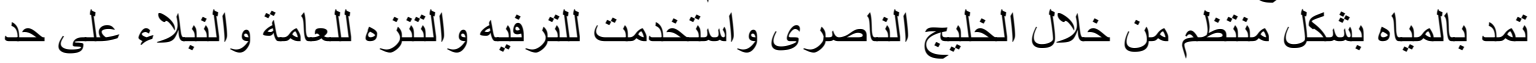
سواء.

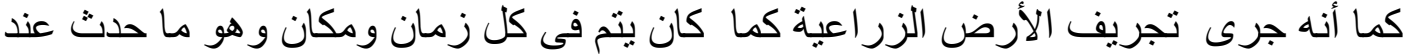

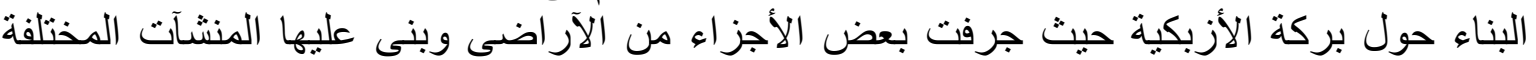

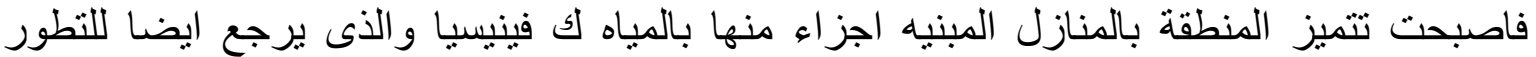

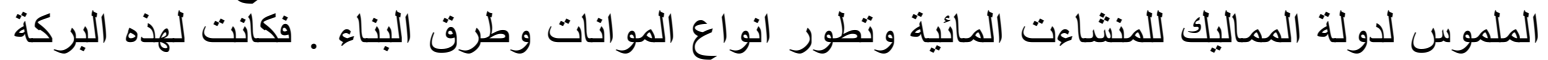

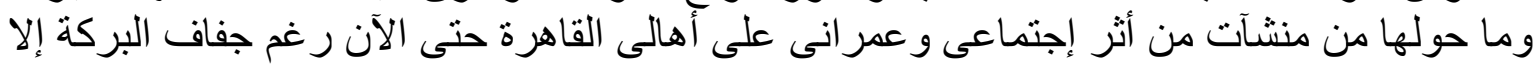

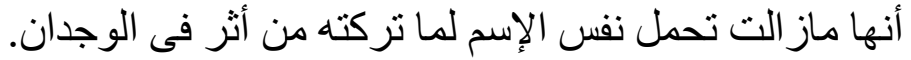



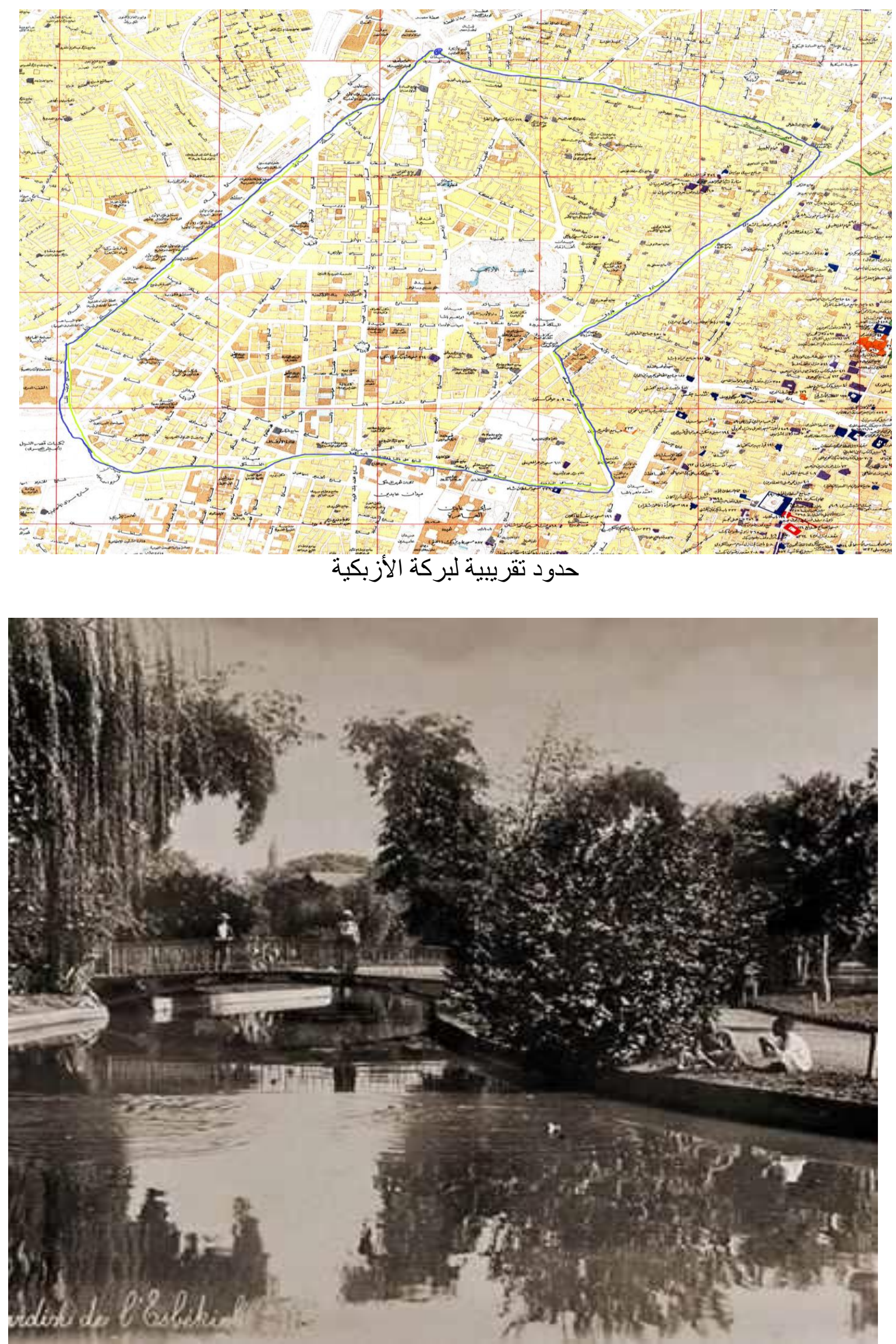

بركة الأزبكية فى القرن الـه 


\section{حو انشي البحث}

كانت منطقة المقسى هذه تعرف فى العصر الفاطمى باسم قرية أم دنين التى كانت موردة ترسو فيها

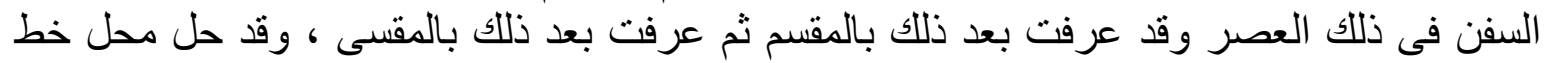

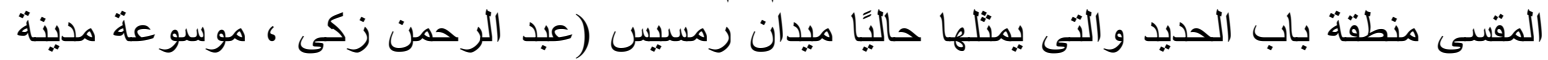

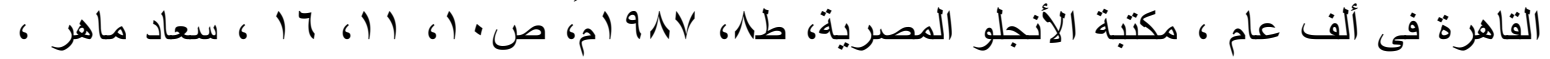

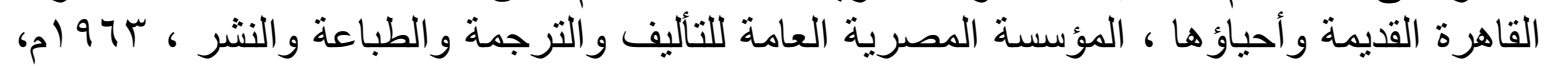

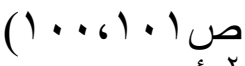

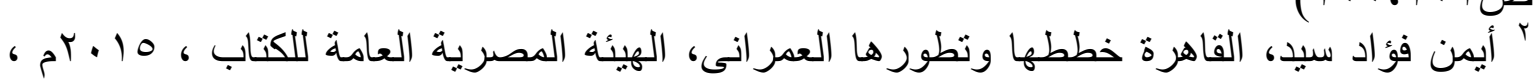

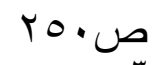

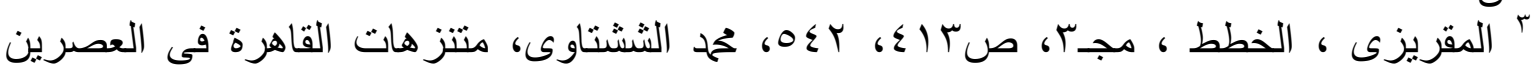

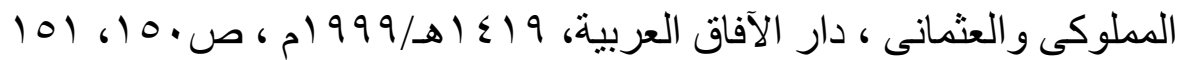

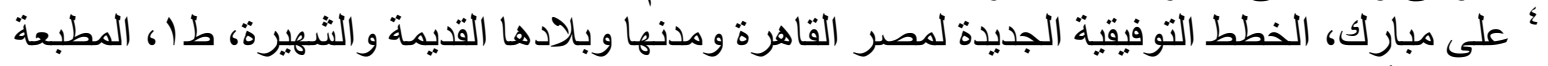

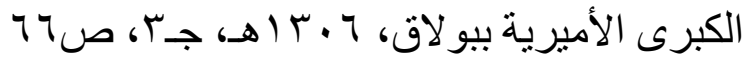

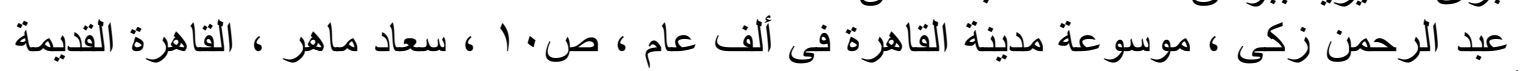

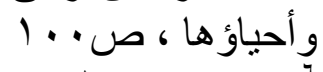

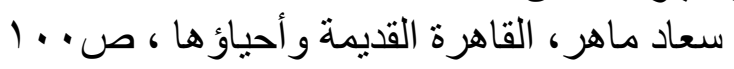

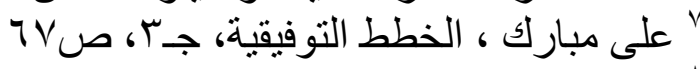

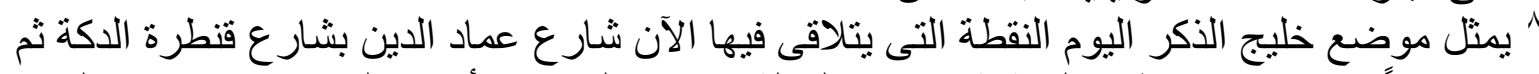

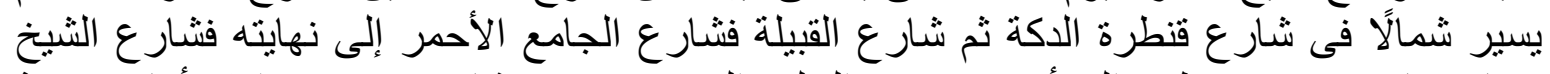

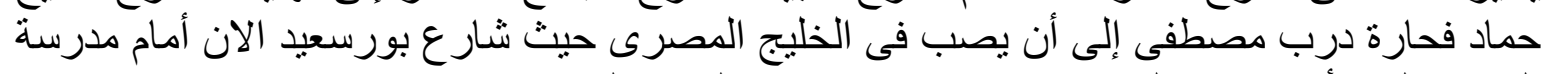

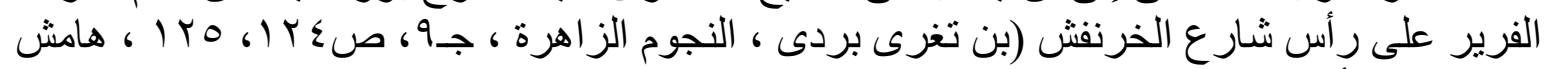

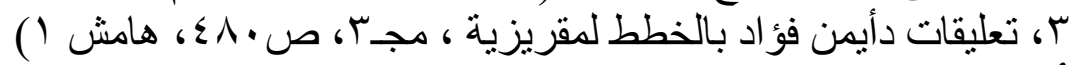

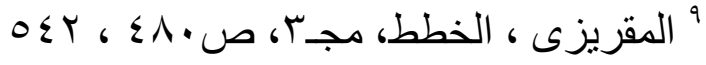

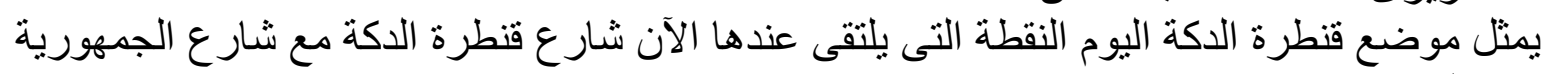

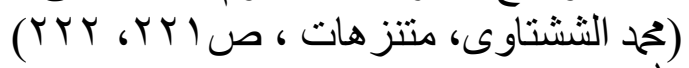

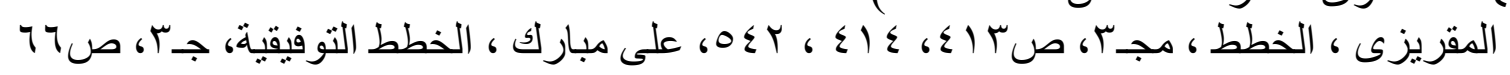

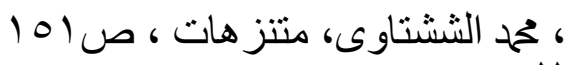

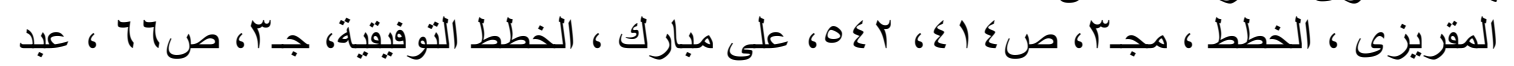

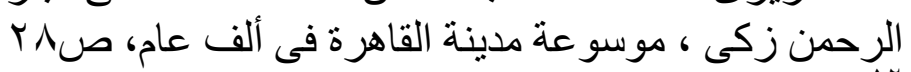

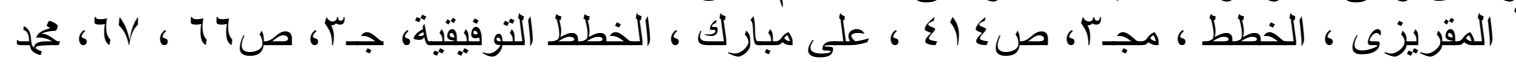

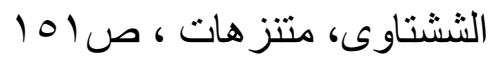

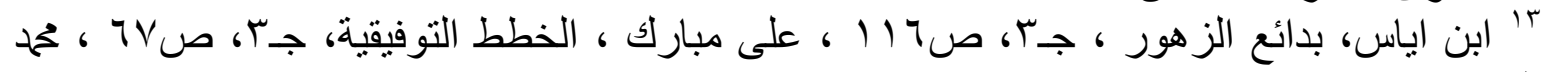

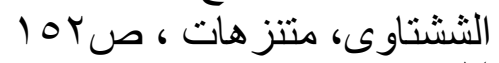

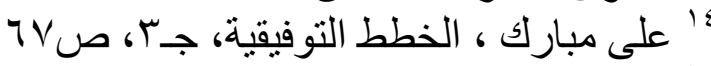

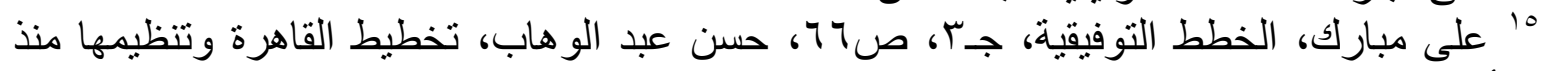

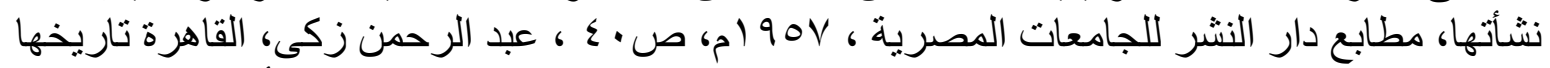

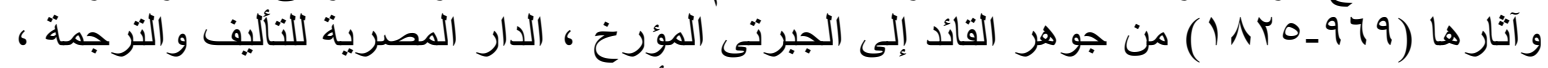

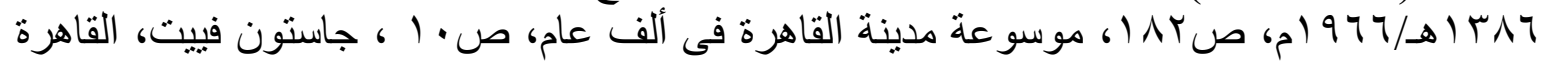

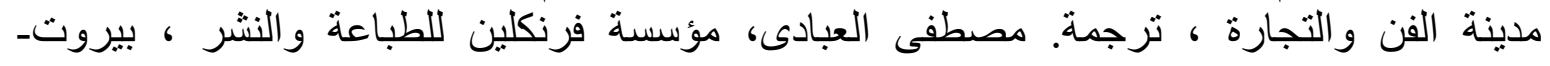




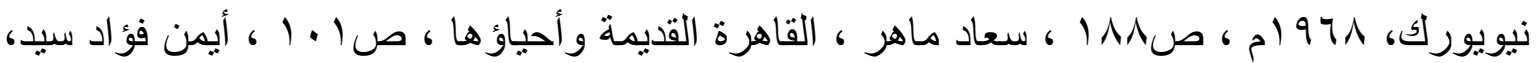

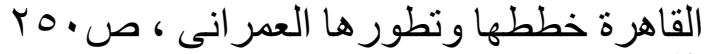

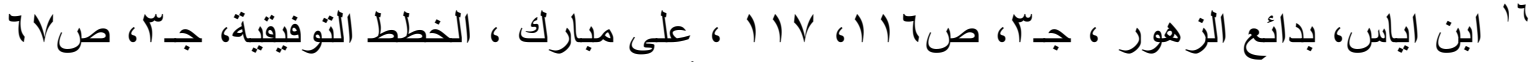

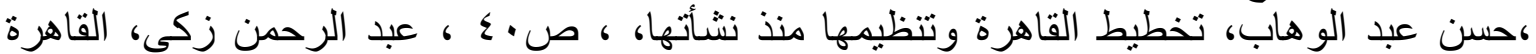

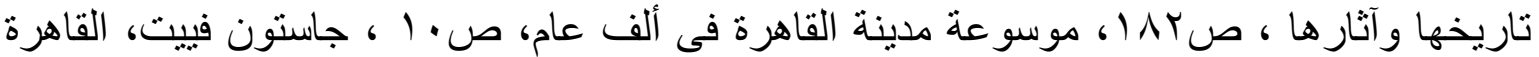

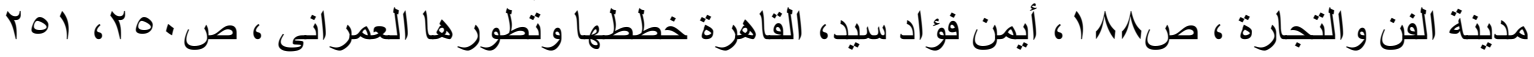

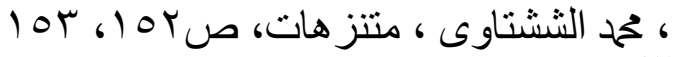

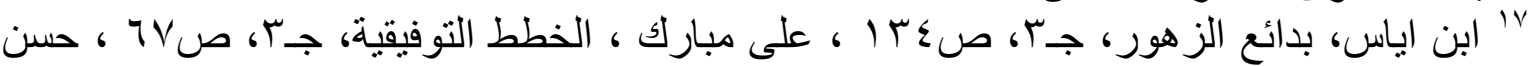

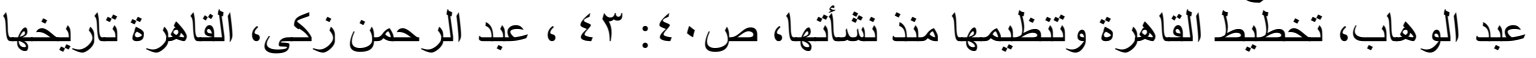

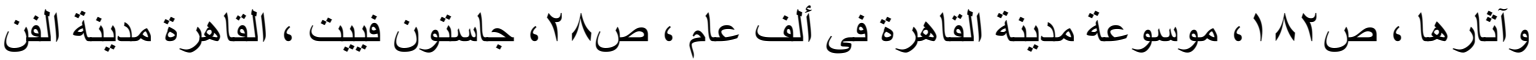

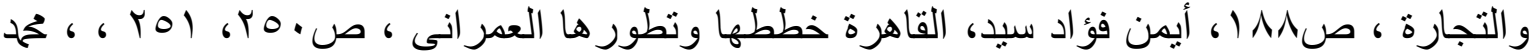

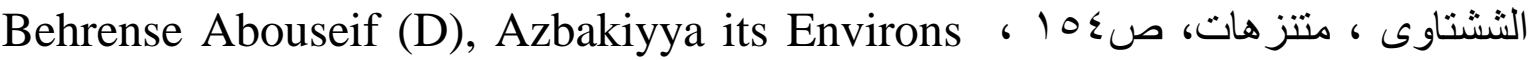
from Azbak to Ismail (1476-1879), suppl. Aux Annales Islamdio, Cahiern.6.

Le Caire, IFAO 1985., p.23

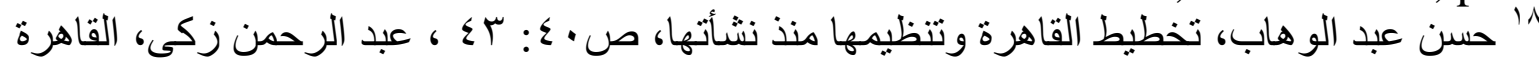

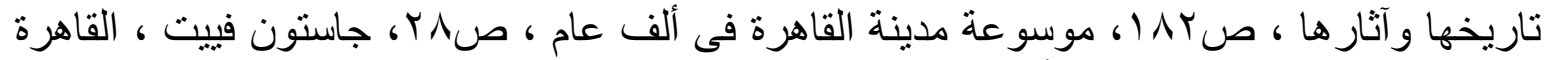

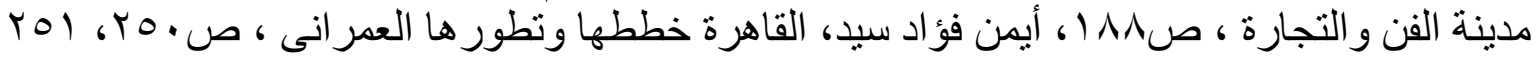

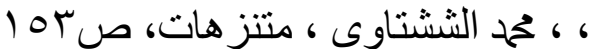

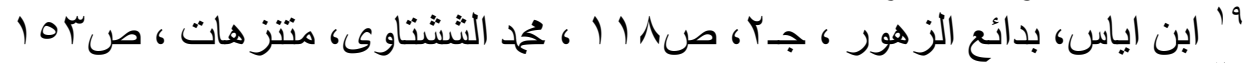

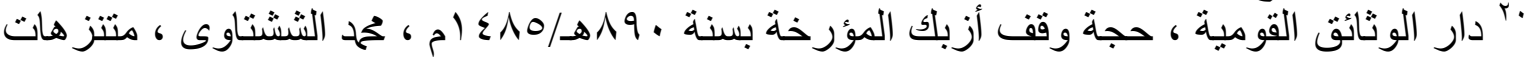

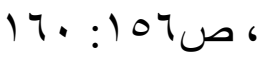
' ب للاستز ادة عن الدور و القصور التى كانت ببركة الأزبكية انظر : حسن عبد الوهاب ، تخطيط القاهرة

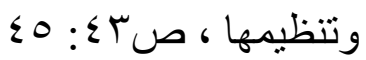

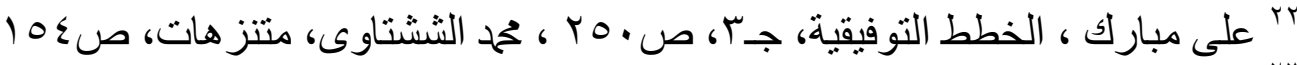

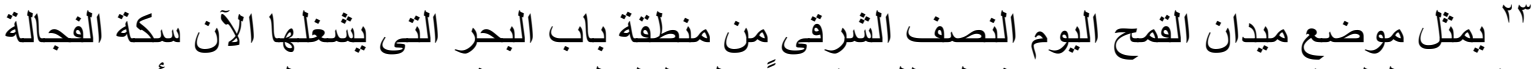

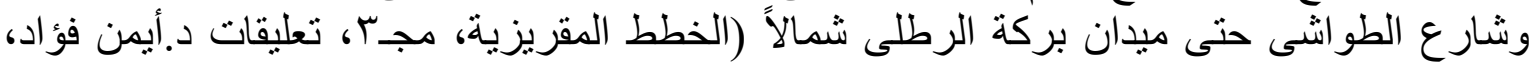

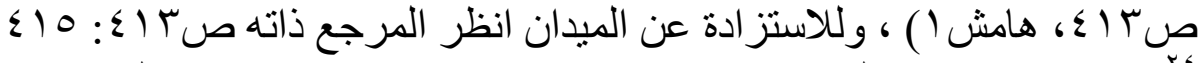

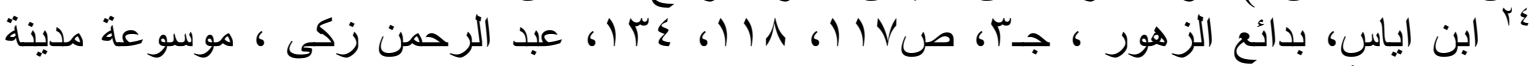

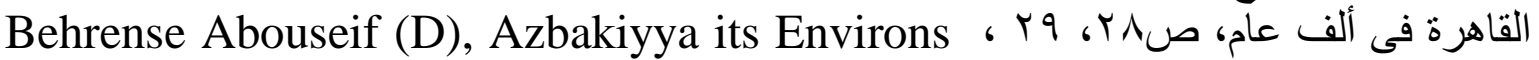
هامئ from Azbak to Ismail

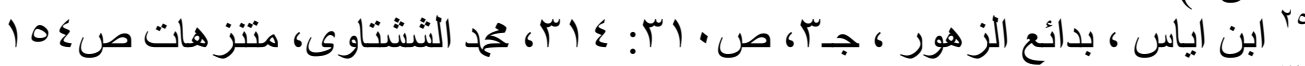

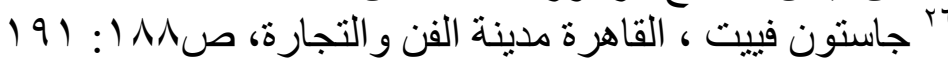

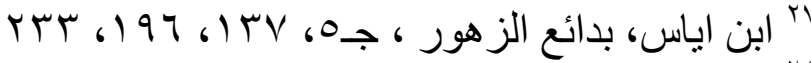

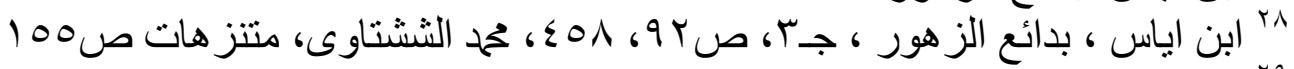

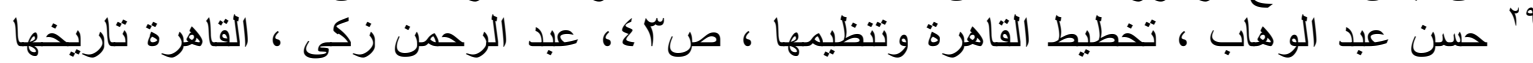

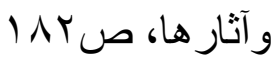

